\title{
Misuse of the peer-review system: time for countermeasures?
}

\author{
Idea and coordination: Hans Ulrik Riisgård
}

Marine Biological Research Centre (University of Southern Denmark), Hindsholmvej 11, 5300 Kerteminde, Denmark

\begin{abstract}
Contributors: Otto Kinne, Tom Fenchel, Everett Fee, Ray Hesslein, Jim Elser, Mary Scranton, Jon Cole, Nelson Hairston, Elizabeth Canuel, Ronnie Glud, Claus Nielsen, Peter Beninger, Rune Waagbø, Gro Ingunn Hemre, Gideon Hulata, Tore Høisæter, Donald McLusky, Ron Kneib, Sandra Shumway, Richard Warwick, Lars Hagerman, Poul Scheel Larsen, Jörg Ott, Peter C. Dworschak, Ferdinando Boero, Josep-Maria Gili, Katja Philippart, Matthias Seaman
\end{abstract}

\begin{abstract}
The peer-review system is overloaded. This causes problems for reviewers and editors. The focus of this Theme Section (TS) is misuse of the peer-review system by repeated resubmission of unchanged manuscripts (mss). A number of editors and experienced reviewers were invited for comments. Most contributors have seen examples of authors resubmitting mss to new journals after rejection without considering the criticisms of former reviewers. No contributor objects to resubmission of mss to other journals, but all object to authors resubmitting a rejected ms practically unchanged to another journal. For some journals this is not a serious problem, but for others this practice is common and it needs to be stopped. It is fair to give authors a chance for a second opinion on their mss. Most authors take reviewer's reports into consideration before sending the ms to another journal, but many never inform the new journal that the ms had previously been rejected.
\end{abstract}

Resale or republication not permitted without written consent of the publisher

\section{INTRODUCTION}

The peer-review (or refereeing) process is often underappreciated in its importance for scientific publishing. Peer reviews assess the quality of manuscripts (mss) and the significance of the research conducted. The peer-review process influences which scientific results are published and where, and thus what impact the results are likely to have. Anonymous reviewers (or referees) are the backbone of this filtering process.

Acting as referee and serving on editorial boards should be recognised as essential contributions to science, and be rewarded appropriately. These statements were supported by a number of leading editors and experienced reviewers who contributed to a previous Theme Section (TS) in Marine Ecology Progress
Series (MEPS; Volume 192): 'The peer-review system: time for re-assessment?' (Riisgård 2000).

As with any type of filter, the peer-review system can be clogged by the material it is intended to remove. It also became clear that it is difficult for many referees to cope with all the mss that they receive for review. One source of the problem was identified as the 'publish-or-perish syndrome', which exists for 2 reasons: the desire of the individual researcher to achieve excellence in his/her chosen field, and the need for an objective standard on which hiring and promotion of scientific staff can be based. This has led to an explosion in the number of submitted mss. According to this TS it should no longer be 'free' to submit a ms to a scientific journal: a 'payback in kind' was favoured by the researchers; i.e. authors must be willing to review for the journals in which they publish (ratio $\sim 3: 1$ ).

MEPS has facilitated a continuation of the peerreview debate on its website (www.int-res.com/forum/ peer_review.html), expanding issues raised by previous contributors. 'Contribution 2' by Ron Kneib argues that there is a substantial imbalance between positive and negative consequences of submitting a ms. For authors' ms submission and re-submission always holds the potential for improvement and publication but relatively little risk of negative consequences. If mss of low quality carried a greater risk of negative consequences for the authors, this would discourage re-submission and save time with only minor loss of information to the scientific community.

Not only overloading and insufficient recognition of the reviewers' work threaten the peer-review system; misuse and selfish conduct also jeopardize the system. 
As pointed out by Everett Fee in the previous debate (see Fee's contribution in Riisgård 2000), vexing problems are caused by scientists who reject (or ignore) review requests. 'Almost all people who refuse to review are senior scientists, and ironically, they continue to submit mss to the journal, taking it for granted that they will be reviewed. It would be fair to reject without review any submission that is authored or coauthored by someone who was asked 3 or more times during the previous 2 years to review for the journal but accepted none. Until there is a penalty associated with refusing all review requests, the problem will not go away' (p 307).

In spite of the fact that peer review is a crucial component of science (see also Kinne 1988, 1999, 2003, Fee 1998) only few concrete suggestions have been made to render the unpaid and anonymous referee work more attractive. However, this question was recently raised in an Editorial of Aquaculture Nutrition (Anonymous 2003): 'As a first step, employers should acknowledge refereeing as part of a scientist's job and this activity should be given merit in scientific evaluations' (p 65). While we are waiting for universities and other research institutions to follow this excellent proposal, most referees will continue to work for the peer-review system, either because they are responsible persons, or because they think that refereeing and serving on editorial boards promote their careers. The latter may be an illusion in light of the scant official acknowledgement and compensation they receive.

\section{PEER REVIEW IN THE SCIENTIFIC PROCESS}

Practically no historical accounts of the development of peer review exist, but the beginnings of 'peer review' have been associated with the Royal Society of London when it took over responsibility for the Philosophical Transactions in 1752 (Kronick 1990). There are many similarities between the way early editors carried out their job and the modern practices of peer review (or refereeing). Institutionalization of the process took place mostly in the 20th century in order to handle an increasing number of mss submitted and to meet the demands for expert authority and objectivity; but the practice of editorial peer reviewing did not become general until after 1945. Peer review of mss was first introduced when editors lacked the expertise to make decisions in specialized fields (Burnham 1990).

The initial aim of peer review was to improve mss, but today it often seems to be perceived as an unwanted obstacle to get round rather than an opportunity to obtain advice and assistance from colleagues. Academic advancement, research funding, and insti- tutional reputations increasingly depend on peer reviewed publications as a measure of quality work although this was not the initial aim of the peer-review system. As a consequence, the peer-review system is now overloaded and-illogically - also inadequately supported by employers, research foundations etc. as evidenced by the insufficient official acknowledgement that reviewers receive. A new phenomenon is an increasing number of authors that prefer not to benefit from the anonymous review work carried out by their colleagues. Instead they misuse the system by resubmitting again and again their rejected mss without paying attention to the constructive criticism made by the reviewers.

Besides the examples already given by the contributors to this TS, a number of other, more subtle ways of cheating the peer-review system exist. In an attempt to avoid critical review an author may send the ms directly to a feared review editor to obtain critical comments as a friendly gesture. Later, when the ms is submitted to the journal without the friendly criticism being disarmed, the editor will see that the reviewer is already mentioned in the acknowledgement, and then the ms is very likely to be sent to another, less critical reviewer. Authors may also in the accompanying letter ask the editor to avoid using a particular reviewer, or enclose a whole list of unwanted reviewers etc., only the fantasy sets a limit of how authors may try to circumvent or cheat the peer-review system.

Many mss are published with more or less severe defects which would have been revealed if the peer review system operated more perfectly. Post-publication critique has often to wait until a paper is published several years later by authors who have objections. Recently, however, MEPS has started to offer an opportunity to exchange views in the form of 'Comments' that are critical re-assessments of published works, and 'Reply Comments' that are answers by the authors criticised. This direct post-publication critique is being used by an increasing number of scientists. L\&O has a similar system which seems to serve the scientific process well, not only by mending holes in the peerreview system, but also to reveal important disagreements between competing research groups.

The question is: has the current application of peer review outstripped its initial aims and abilities? Generally, the unwritten rules of the peer review game seem to be accepted within the scientific community. In spite of the importance, little sound scientific research has been published on the health and effectiveness of the review process. Some sceptics believe that the peer review process exercises little control over what is published. Some even think that unscrupulous authors persistently forward their mss from journal to journal in a random fashion until eventual publication. As a 
reviewer I often have the impression that certain editorial offices operate more like paper-exchange offices where a secretary just sends you a standard letter without the editor's signature, and later on nobody acknowledges receipt of your review report. To me this is a sign of degeneration of the peer-review system.

Investigation of the process whereby scientific work is selected and published is an evolving science within biomedical publication (Rennie et al. 2003). To measure the effectiveness of peer review in evaluating medical mss, the editorial office of the American Journal of Surgery (AJS) conducted a search of publications from 1984 to 1992 for mss that were identical or similar to those rejected by AJS in 1989 (Sweitzer \& Cullen 1994). A total number of 125 mss were rejected, and $62 \%$ of mss rejected remained unpublished in the core medical literature. The overall implication is that the review process effectively prevents many lowquality or duplicate mss from being published in the indexed medical literature.

A similar examination of the aquatic science literature would be interesting. To me it is strange that the aquatic scientific community has so many active scientists involved in peer review and quality control who apparently find it satisfying to do a backbreaking referee job on the basis of hardly any research analysing the effects of their own work. Close co-operation among different journals in related areas and crosscheck could throw light on how effective the peer review system actually is and to what extent misuse by irresponsible authors is a real problem. Questionnaires could also be sent by editors to review editors and referees to obtain information about the constitution of the peer-review system. Thus a number of questions were sent to 65 review editors of the journal Aquatic Microbial Ecology, and 40 responses were received by the Deputy Managing Editor John Dolan (see website MEPS Discussion Forum of peer-review 'Contribution $3^{\prime}$ ). This study revealed overall satisfaction with the average quality of scientific publications and with anonymous peer review as presently practised.

There is a quality hierarchy among scientific journals, based on the rigour of their peer review. Authors can work their way down until their ms finds its own level. It takes time for new authors to find their level and to adjust their mss to the tough conditions of the hierarchical filter. During this 'adjustment period' most authors have had mss rejected by journals in the upper end of the quality hierarchy of journals. An experienced author always knows when a ms is 'too good' or 'too bad' for a particular journal, and consequently s/he picks out a journal at the right level with the right profile so that the probability of acceptance is high, although the chance of encountering difficult reviewers always remains.
It is not a disgrace to have a ms rejected, particularly not during the 'adjustment period'; but just to resubmit the same ms unchanged to journal after journal without taking note of the reviewers' comments and advice brings disgrace to the author. To me it seems appropriate if all journals enacted a resubmissions policy that prevents such misuse of the reviewers' services. Some, but not all, of the contributors to this TS agree that there is a need for countermeasures to protect the peer review system. Nevertheless, the present discussion may help participants in the peer review process to be more conscious of strengths and weaknesses of the system, and help to protect it from unprofessional conduct by certain authors.

\section{CIRCULATED LETTER}

This TS focuses on the misuse of the peer-review system and how to protect the system. To start a discussion, I circulated the following letter to various editors and experienced reviewers for comment:

\begin{abstract}
'On the basis of peer-review, many mss are rejected by most journals, but some authors unscrupulously resubmit their rejected paper to another journal for another peer review without any changes and without revealing to the editor that the ms has already been peer-reviewed by another journal. To submit a paper to a scientific journal is to ask for other people's valuable time. Many authors do not seem to be particularly conscious about this fact. Before submission of their first imperfect ms all new authors should be instructed how the peer-review system works. The importance of following the (so far) unwritten laws should be emphasised, and it should be made very clear that misuse of the overloaded peer-review system cannot be tolerated. The peer-review system needs protection against misuse and it is time for introducing effective countermeasures.'
\end{abstract}

\section{COMMENTS FROM SCIENTISTS}

MEPS has now modified the guidelines for InterResearch (IR) authors, so that 'if a ms has previously been submitted to any other publication outlet, the former reviews and author's replies should be enclosed.' One purpose of my letter was to find out whether other journals intend to apply a similar rule to protect the overloaded peer-review system. Opinions are divided (see below) and there are many aspects to take into consideration before common countermeasures are imposed to protect the traditional peer-review system. The comments are arranged chronologically by time of receipt, but all respondents have had the opportunity to read all contributions and to adjust their own comments. 
Otto Kinne (Editor, Marine Ecology Progress Series; Marine Biology; Diseases of Aquatic Organisms). Often criticized and sometimes predicted to be doomed, the peer review system has guided scientific publishing for more than 250 years, and presumably will be with us for a very long time to come. There are numerous inherent problems and shortcomings in peer reviewing, but no one has yet been able to develop a better system for controlling and improving the quality of scientific publications. The peer review system depends on the voluntary extra work of established scientists who devote a considerable part of their own valuable time to evaluate and improve the work of others-including that of potential competitors. This noble service to science should be acknowledged. MEPS is presently considering to publish lists of all referees consulted (in addition to our Contributing and Review Editors) at the end of every 10th volume.

One problem of the peer review system is that some authors abuse the reviewers' services by submitting rejected mss to another journal without taking the criticism previously offered sufficiently into consideration and without revealing that their ms has been previously reviewed and rejected. The temptation to take such a 'shortcut' may be understandable, considering the 'publish or perish' atmosphere prevailing in the world of science today. But by taking this shortcut, authors place their own reputations at risk and deprive themselves of the benefits of peer review. If they disagree with the reviewers' objections and/or editor's rejection, they should disarm this criticism in a revised version before submitting it elsewhere (see InterResearch: Guidelines for authors).

Editors must admonish authors who send unrevised rejected mss from journal to journal (and thus from referee to referee). Admonishment is necessary, not only for the sake of the journal or the good of science, but also for the benefit of the authors.

Tom Fenchel (Editor, Ophelia). No doubt — the massive amount of papers now being published presents problems for anyone involved: overburdened referees and editors, and not least readers who cannot keep track of the literature in their own field. Most would probably also agree that many published papers are, in fact, superfluous and a result of the 'publish or perish' syndrome. So the appearance of suggestions how to make life easier is not surprising.

And so the observation that papers rejected by a journal - perhaps even by several journals - eventually are published somewhere; in some cases even in a totally unaltered version. As a referee I have-like many of my colleagues - experienced to receive the same ms twice (and in on case 3 times) from different journals. In that case I usually return the ms with a remark that I have seen it before. It is easy to become upset by the phenomenon as a referee and as an editor (if the latter is somehow informed about it).

But - and I am not only playing devil's advocatethere is another side to the coin. I can see the following problems in trying to stop the practice:

1) How serious is the problem - is it really a large burden on referees and editors?

2) Mss may be rejected for reasons other than scientific substance. Mss may not fall within the editorial policy of a given journal. The journals Science and Nature reject some $90 \%$ of submissions, many of which may be of high quality, but not considered of sufficient general interest, to represent a sufficiently 'sensational' discovery, or they do not fit in for some other reason. Also, in these journals most papers are rejected without refereeing.

3) Most important: refereeing is-like all other human endeavours - not perfect. Referees are not gods! To be sure, most recommendations for rejection are probably well founded and reviewer's suggestions for changes will in far the most cases improve a ms. But sometimes the author is actually the real expert, and sometimes referees misunderstand papers or express some sort of idiosyncrasies. There is no doubt that while it is the exception, rejection of a ms may be a big mistake. The classical example is the paper by Krebs in which he first described the citric acid cycle: it was rejected by Nature. There are undoubtedly many more such examples involving perhaps less monumental, but still important discoveries. Although it is fortunately rare, it must finally be recognised that some referees reject or try to delay publication of their peer's papers with motives that are less than honourable.

And so I think it is fair to give authors a chance for a second opinion on their ms. It may involve some more work for referees and editors, but trying to stop additional submissions also involves a cost. Finally I believe that sanctions against a second submission are difficult to enforce in practice - if the authors do not provide the information the 'case' will only be disclosed by chance (that is, a reviewer receives the ms twice and informs the editor). When a referee receives an unaltered $\mathrm{ms}$ for the second time I believe-as already mentioned - that the referee should return the ms to the editor. Not necessarily to save his or her time - or to indicate that the author is an idiot. It could also reflect the attitude that maybe I was wrong - and so someone else should look at it.

Everett Fee (Editor-in-Chief, Limnology and Oceanography). Thank you for giving me an opportunity to comment on the issue of resubmission of rejected mss. I am aware of only a few cases where Limnology and Oceanography (L\&O) was the 2nd choice of an author (the first being Science and Nature), so this is not really a big issue for us as it 
appears to be for journals that receive resubmissions of our rejected mss. I circulated your e-mail to the L\&O Associate Editors for comment. Based on these comments and my own perception that this is not an important problem for L\&O, we will not follow the lead of MEPS in requiring authors to divulge prior submissions to other journals.

As before, the biggest problem that I see with the peer review system is authors who tell me that they are 'too busy' to review for L\&O. Invariably, these are scientists in senior positions who regularly submit mss to L\&O. In my view, it is selfish of them to expect others review their papers, but at the same time refuse to return the favour. Below is a summary of the L\&O Associate Editors replies:

Ray Hesslein (Associate Editor, Limnology and Oceanography). My feeling is that an author should inform the journal if the ms has been submitted and rejected by another journal. That gives L\&O the information it requires to follow up on the rejection. I am not sure that the author should be required to address all issues of the previous review. Problems from one journal may not be problems at another. As well, some rejections are a matter of an irreconcilable difference with a particular reviewer that the author feels strongly about. L\&O reviews have to stand on their own.

Jim Elser (Associate Editor, Limnology and Oceanography). My experience as author, having had many papers rejected(!), is that I have always taken the reviews into consideration before sending [the $\mathrm{ms}$ ] to another journal, but I must say that I have never informed the new journal that the ms had previously been rejected. Certainly did not seem in MY interest to do so. I do not agree with the editor of this MEPS Discussion Forum that it is 'unscrupulous' to withhold the prior status of a ms from a journal, though it is unscrupulous to deliberately ignore valid criticisms provided for a ms.

My experience as Associate Editor (Oecologia, Ecol. Letters, Ecol. Applications, L\&O, Am. Nat.) is that I have never handled a paper for which the authors indicated that it had been previously rejected elsewhere. (Does this mean that I never handled a previously rejected ms? Or that nearly all ecologists are 'unscrupulous'? I would say 'no' to both questions.)

I think that the issue of ignoring previous peer review comments prior to resubmittal elsewhere is a fundamental issue of scientific / personal ethics and really there is little that a journal can do about it. I do think that stating that the work has previously been rejected elsewhere unfairly prejudices the review process (given that we know that the review process can often be capricious and stochastic); each paper should be reviewed on its own merits.
Mary Scranton (Associate Editor, Limnology and Oceanography). I agree that a forced notification of prior rejection would be perceived by most authors as prejudicing their paper. Especially if the rejection is from Nature or Science, this is clearly not true, but most authors would not want to say that they had been rejected. (As my son would likely say, who wants people to know you have been rejected by someone you asked to the prom?) Many rejections (including those we give at $\mathrm{L} \& \mathrm{O}$ ) are because the paper is not suitable for the present journal, etc. and not necessarily because the paper or the research is not of high quality. Unless the author were to provide all letters from reviewers, editors, etc., we would still not be getting the 'whole picture'.

On the other hand, I agree that authors should consider any previously obtained reviews. In cases where a paper was NOT of high quality and was resubmitted, sometimes we end up asking the same reviewers but not always. I guess this provides extra incentive to be rigorous in our decisions.

Jon Cole (Associate Editor, Limnology and Oceanography). I would not like to see L\&O adopt a policy like that at MEPS where prior rejections from other journals are made part of the package. The stochastic element is high in journal rejection and acceptance, especially at some journals, and I think the new (L\&O) AE and new reviewers might be prejudiced by the prior package in a bad way.

I think L\&O should ask authors, perhaps as a matter of policy, to consider fully any rejections and reviews they may have received on a prior submission and take these recommendations seriously before sending a paper to $\mathrm{L} \& \mathrm{O}$.

There is a food chain here. L\&O is not likely to get the rejects from say, Hydrobiologia, or J. Environ. Qual. We are very likely to get papers that are derived from rejections at Nature or Science and a few other journals. I think that is OK.

Nelson Hairston (Associate Editor, Limnology and Oceanography). I have on occasion reviewed the same paper for more then one journal. It is a bit annoying to see the same thing twice--especially when no changes were made in response to my previous comments. But in this case, producing the new review is pretty easy! I did get the same paper from 3 separate journals once and in that case told the editor of the third journal that I felt it was unfair to the author to have the same referee over and over again and declined to review it.

Elizabeth Canuel (Associate Editor, Limnology and Oceanography). Several factors are considered when deciding whether a paper is acceptable for publication including quality of the work as well as whether the paper is appropriate for a particular journal. For these reasons, it is unfair to bias the review process by 
requiring that authors divulge any previous rejections. We should, however, encourage authors to give serious consideration to previous reviews before submitting their ms for publication. We should also encourage authors to acknowledge reviewers in their published mss.

Ronnie Glud (Associate Editor, Limnology and Oceanography). I have not much more to add to the previous L\&O AE's contributions, with whom I generally agree. However, as a frequent reviewer I do not think 'journal jumping' of unqualified papers is a big problem. We have all seen examples of authors resubmitting papers to new journals after rejection without considering the critics of former reviewers, but I believe that it actually is a minor problem. Further, the likelihood that the resubmitted paper ends on the table of the same reviewers is relatively large - and in those instances where no changes have been made it is of course the duty of the editors to strongly point out to the authors that this is an unacceptable behaviour.

To start registering submission, rejections, and reviews in a global data base with the aim to eliminate this minor problem would in my opinion be 'overkill'. Further, for the reasons given by the other L\&O editors I do not find it fair to demand that authors explicitly should state if a paper previously has been rejected by another journal - and I do not think it would change the behaviour of the few authors that do 'journal-jumping,' they can still submit an unchanged paper. To evaluate the work of previous reviews and decisions of a submitted paper would increase the burden of the peer-review system rather than ease the work load.

Claus Nielsen (Former editor, Acta Zoologica). The peer review system is under attack, but I have yet to see a good alternative. The burden on the good referees is increasing, but I suppose that this is mostly a result of the increasing numbers of scientists and mss. Every editor tries to get the best colleagues to review mss. The problem of submission of previously rejected mss without regard for criticism from the referees seems small. As pointed out for example by Tom Fenchel, rejections are of different types. Papers can be rejected because the journal is not the right place, because the results are not sufficiently 'sensational', because the presentation/discussion of the results is not sufficiently good, because the style/language is not in order, and then finally because the scientific contents are not worth publishing. I can only hope that editors will let authors know the reason for rejection and offer all the help they can. If the authors will not accept criticism/help, there is not much we as editors can do. 'High-profile' journals may insist on being informed about previous submissions, but I wonder whether this will make much difference. If a referee receives a ms a second time and recognizes that his criticism has not been followed, I think that he should return the ms with a short note outlining his previous criticism and stating that his advice has not been followed. In the end it must be up to the journal to make its own decision.

Peter G. Beninger (Laboratoire de Biologie Marine, Université de Nantes, France). The editor of this MEPS Discussion Forum suggests that authors whose papers have been rejected elsewhere be required to state this upon re-submission. I think this is reasonable, but I also do not think that this should be a reason for treating it differently from any other submission. I have seen enough in this process to know that occasionally, very good work can be rejected by ill-informed or partial reviewers. The starting point of this section was the (I think relatively uncommon) misuse of the peerreview system by authors, but we should also be prepared to act upon the few, but troubling cases of 'delinquent reviewers'.

Identifying delinquent reviewers is very difficult, because authors whose work has been rejected may not be completely objective in their assessments of a reviewer's performance. There are, however, some telltale signs which should raise a red flag in a negative review: vague reasoning for rejection, extremely short review, and excessive insistence on citing the reviewer's own work or on using the reviewer's pet technique, overall dogmatic and peremptory tone. These are not infallible, but should incite an editor to proceed with caution.

Rune Waagbø \& Gro Ingunn Hemre (Editors, Aquaculture Nutrition). There is no doubt about the great importance of the referees work. However, stating that the ms have been previously submitted to any other journal and rejected may imply that the new editor or referees are biased against the paper. It is never nice to be the second choice. Perhaps the paper needed to be looked upon with new eyes by a journal and referees more compatible with the topic of the paper. As an example, highly rated scientific journals may have editors (or referees) who do not accept (understand) modern statistics and new methodologies, and thus reject these submitted papers. Misuse of the referee system by low quality papers may of course happen. This could partly be prevented if the editors could be more involved in the process, by directly returning or rejecting papers that do not fit the topics of the journal. Thus, we do not support the view that authors resubmitting papers rejected from other journals should have to state this and give details about earlier treatments.

Gideon Hulata (Section Editor, Aquaculture). The following are my personal observations/comments on the subject matter. I can't remember even one case where a ms submitted to my section (genetics) in the journal Aquaculture was sent to referees and they 
have complained about seeing it before for another journal. If there was one that I fail to recall, then it is still a rare event. So this doesn't seem to me to be a serious problem. Other Aquaculture section editors may have had different experience though. The bottom line, I don't think I am going to recommend my Senior Publishing Editor to adopt any different policy from that we currently are working with.

Having said that I generally agree to what Elizabeth Canuel has contributed above to this discussion. The reasons for rejecting a paper by another journal vary from case to case. Often (as happened to me too) it is because it is not appropriate to the scope of the journal, and not necessarily due to poor quality. Thus, it would be unfair to bias the review process by requiring that authors disclose previous rejections. It doesn't matter to me and I don't want to know this. If my peer review process suggests that the paper is suitable for our journal, so be it. However, I definitely agree that authors should give serious consideration to previous reviews before submitting their mss for publication. The question is how do we make it happen? I have a strong feeling that some authors may be exploiting the peer review system by having reviewers help them improve their mss. This is a difficult issue. On one hand, I appreciate those reviewers who spare time and help authors (especially those who are not native English speaking) improve the prose of their papers, not only the scientific content of it. On the other hand, I realize that if an author does not acknowledge the help he has received, and sends it to another journal, he has taken benefit of the good will of a previous reviewer who has invested precious time in helping him. So, we should encourage authors to acknowledge reviewers in their published mss. Some do, some don't. Then again, how do you make this happen? One has only control of doing so within his/her journal.

Tore Høisæter (Editor, Sarsia). My experience as editor and referee is that this 'misuse' of the peer review system is not very extensive. I know of only 3 cases, one in which I was approached by another journal to review a ms that had been rejected in Sarsia, one in which it appeared during the revision process that the authors had received similar advice in an earlier review process, and one in which a prospective referee informed me that he had heard rumours that the ms had been rejected by another journal. When confronted by this the author had a reasonable explanation, the ms had been rejected without referee-treatment and not for any valid scientific reason. If I should have received a message that any mss sent to referees who have already rejected the ms for another journal, this has slipped my mind. I do know of a few cases where articles rejected in Sarsia have been published in other journals though. All in all, not an extensive problem.

I do sympathise with the many contributors to this TS who have expressed their concern that a rejection in a journal which is not near the top of the 'food chain', might prejudice the editor. I believe that every scientist, especially the young and aspiring ones, should have a chance of a second opinion. If the ms should end up on the table of one or more of the same reviewers as before, this should not be a great burden on those people, as they could easily return the ms. Usually they get a chance to inform the editor through Email even before they receive the $\mathrm{ms}$ in question, as the title and authors would ring a bell. Of course we would strongly recommend our contributors to seriously take any comments or recommendations from reviewers of earlier drafts of the paper into consideration before resubmitting to Sarsia or any other journal for that matter.

Donald McLusky (Editor, Estuarine Coastal and Shelf Science). I discussed the message with my colleagues at an Elsevier meeting, and basically they and I agree with Fenchel's views.

Ron Kneib (Former Contributing Editor, Marine Ecology Progress Series). The fundamental concept of peer-review is irreproachable and it should be clear that this debate is not about its value or relevance. It is in the application of the concept that the flaws and foibles appear because peer-review relies on the experience and opinions of a subset of the scientific community. For any individual ms, that subset can be very small (2-3 reviewers and an editor) and variation in outcome can be expected simply because of the sample size of polled opinions. Any such bias or vagary in the system holds for mss that are accepted as well as for those rejected for publication. The integrity of the science community is damaged by those who recommend either rejection or acceptance of mss for largely self-serving purposes, but so too is the process compromised by authors who knowingly submit inferior mss with little intention of making a contribution to the field.

As a self-regulating system, the integrity of peerreview depends on the general attitude of the entire scientific community from which both authors and reviewers are drawn ...there is, at least, an implied expectation of adherence to a set of common principles or standards upon which participants in the process base their judgments. Even the appearance of impropriety damages the integrity of the process for all. As the scientific community grows and changes, is it realistic to expect that participants in the peer-review process will continue to act appropriately if not reminded of their responsibilities, and chastised if they violate the collective trust? I applaud Inter-Research for taking 
a leadership role in attempting to address the issue with their new disclosure policy, though it is difficult to see how its efficacy will be evaluated.

Having participated in the peer-review process as an author, reviewer and editor I can bear witness to a variety of misuses of the system, including the repeated submission of rejected mss. Several respondents raised the legitimate issue of the magnitude of this problem, which presently cannot be addressed for lack of objective data.

In a previous contribution to the general website MEPS Discussion Forum of peer-review (Contribution 2) I proposed a mechanism by which the scientific community might begin to assess and monitor the degree to which the peer-review system was being misused by having journals annually publish a list of the rejected mss, much as they routinely acknowledge their lists of reviewers. It is generally recognized that a ms can be rejected for a variety of reasons and most, if not all, authors have had this experience so there should be no stigma attached to the simple fact that an author or ms appears on such a list. However, authors of mss routinely listed by one or more journals would suggest an imbalance between the demands being placed on the peer-review system and the return in terms of an author's contribution to a given field. Availability of such information would allow the development of a type of inverse impact index, and should encourage those who abuse the system to assess their motives before formally submitting mss for peer-review.

No system is perfect ... which means that all have the potential to improve. Striving for perfection may be as much a part of human nature as the inability to achieve it. If the role of the scientific community is to improve human society through research in pursuit of knowledge, should we expect any other group to be less apprehensive or more transparent about questioning, testing and attempting to maintain the integrity of its processes and institutions?

Sandra Shumway (Editor, Harmful Algae; Journal of Experimental Marine Biology and Ecology; Journal of Shellfish Research). The peer-review system is not perfect. It is, however, the best option we have available to provide some level of quality (and quantity) control on publication, and has functioned in this capacity for over 2 centuries. As such, the efforts of peer-reviewers should be recognized, if not by their home institutions as a worthwhile and necessary expenditure of time and effort, then by their peers as a sacrifice of time and effort to preserve the system and enhance individual efforts.

Manuscripts are rejected for a myriad of reasons; poor quality of science is only one of them. Many times it is simply a matter of not being the right venue or lack of space. I do not object to resubmission of papers to other journals. What I do object to are authors who have had a paper turned down who simply place it in a new envelope and submit to another journal, in some cases not even bothering to change the format of the references. This practice is not rampant, but it is not uncommon and it needs to stop. In addition to editing journals, I regularly review for others and have actually received papers from other editors that I had previously rejected myself - and the authors had paid little or no attention to the criticisms offered the first time! In some fields, the likelihood of the same person receiving the paper to review is small. In more specialized fields, however, the likelihood is high and the reviewer pool is small. All too often, I receive notes back from reviewers indicating that they had reviewed the same paper previously and rejected it, noting that no changes had been made. Not only is the author doing themselves a disservice by not taking advantage of the reviews to improve their paper, but to blatantly ignore the efforts of the reviewers is, in my opinion, not only unprofessional, it is unconscionable. Authors should be appreciative of the time reviewers donate on their behalf and, even if they disagree with the assessment of their ms, should have the courtesy to address the reviewer concerns before resubmission - to the same journal or elsewhere. I expect authors to respect the time and effort expended by reviewers (and editors) and to return the favour when asked to review mss themselves.

While I certainly do not expect authors to bow to all reviewers' criticisms (sometimes reviewers are, quite simply, wrong!), I now require a detailed list of changes made (or not) in response to each criticism or comment offered by the reviewers. If nothing else, this requires that the author consider the comments provided.

All too often in the rush to publish, authors lose sight of the fact that their published work is a permanent record and a lasting reflection on their reputation, and not simply another entry on their resume. As my major professor pointed out almost 30 years ago, a published paper and a retraction do not count as 2 publications! Authors should be grateful for constructive criticism that will improve their papers and should view the peer-review system as a gift from their colleagues.

Richard Warwick (Editor, Journal of Experimental Marine Biology and Ecology (JEMBE)). Like now introduced by MEPS, JEMBE also has a policy of asking authors to notify us if submitted papers have already been considered by other journals before, and if so to send us the referees' comments on the ms, and account of how they have addressed these comments, and any other related correspondence with the editor. The 3 editors of JEMBE (Tony Underwood, Sandy Shumway and myself), have asked Elsevier to include a state- 
ment to this effect in the 'Instructions to Authors', but this does not seem to have happened yet. The reason for doing this is partly, as said in the present 'Circulated Letter' from the editor of this TS, to avoid lazy authors simply shopping around their unrevised mss in the hope of finding one that selects less critical referees and of slipping though the net. Frequently in the past I have had mss returned from referees saying that they have already reviewed the paper for another journal, have recommended rejection, and the paper has not been revised in the light of their comments. Sometimes this is detectable if the authors acknowledge the comments of 'anonymous referees', which is a bit of a giveaway!

Obviously refereeing mss for journals is a thankless task, and we need to reduce the burden on referees as much as possible. There are benefits to being honest in this respect, though. I have had mss from authors who have sent me the complete early history of the paper, and on occasions where the referees have been very positive but simply said that the paper was not appropriate for that journal, I have been able to accept it without the need for further external review (that is if the paper is appropriate for JEMBE, of course).

Lars Hagerman (Editor, Marine Biology). I do not know if this is a great problem or not. It is often just a coincidence if an editor discovers that a ms earlier has been submitted elsewhere. The more specialised a research field is, the fewer reviewers are available and thus the probability that the editor sends the ms to the same reviewer as an earlier editor is much higher. This happens to me-both as editor and as reviewer-a couple of times each year. Most authors have, however, understood that the reviewers' remarks in most cases are a constructive criticism and revised their ms accordingly before they submit it to a new journal. I have also experienced recently that authors are honest enough to tell the editor the prehistory of their ms. Those - and I think they are few - who just continue to send an unchanged ms from journal to journal will not stop doing so by instructions saying that earlier reviews should be included. Authors with such low morals will just take the chance. Generally, I think it is important that authors realize that the remarks from reviewers are positive contributions to the ms. Of course, reviewers can be totally wrong but that is also why several reviewers are used for each ms. So far we have nothing better than the reviewer system and the authors should appreciate this by revising their ms where appropriate and reviewers by doing good and constructive reviews. Fortunately, this is so in most cases.

It is of course disconcerting that there are some less serious (and probably incorrigible) authors that cause extra load on the peer-reviewing system by re-submis- sion of rejected and unimproved papers. However, I believe this is a minor problem, and I basically agree with the views of Tom Fenchel, including a hesitation to support a countermeasure such as that adopted by MEPS.

Poul Scheel Larsen (Fluid Mechanical Section, Technical University of Denmark).

The process of peer-reviewing is unsurpassed, as everyone agrees, and editors play an important role in training a next generation of reviewers. After all, it is not only a chore to review, there is also the benefit of pre-publication insight into new ideas, results and developments. The meticulous reading is a good exercise as it may well contribute to improve the junior reviewer's own publications. Therefore, editors could contribute to reduce the load on the well-known specialists by consciously including one or 2 'juniors' along with a 'senior' on a review team. Finally, although it means a marginally extra administrative chore on the part of editors, it is a courtesy to reviewers to always inform them of the ultimate fate of a ms.

Jörg Ott \& Peter C. Dworschak (Editor in Chief \& Assistant Editor, PSZN: Marine Ecology). Receiving a letter from a reviewer that the ms you have just sent to him, has already been recommended for rejection by him when he reviewed it for another journal, is certainly a nuisance for an editor, especially when none of the recommendations have been considered. We believe, however, that it is not a major problem for high quality journals. What may MEPS or L\&O expect to receive, but mss that have been rejected by Nature or Science but may still be of top quality? What should a scientist do with the results of much hard work which she/he believes to be important, but revise the ms and try again? Submitting a ms that has been rejected by one journal to another is a legitimate practice, because reviewing is done by peers (not superiors) with whom an author may disagree. Secondly, the 2 to 3 reviewers entrusted with the task of finding a ms fit for printing constitute in most cases a very small sample of the population of scientists in the particular field and others may come to a different verdict. Thirdly, different journals have different standards for the rejection of mss depending on ms flow and impact factor. Whoever has had a ms rejected by Nature or Science will know, that it takes only a sentence like: 'This is a brilliant piece of science etc., but ....' to kill a ms, despite otherwise excellent reviews. It is, however, good practice of editors to choose their reviewers among the most experienced and respected scientists in the field. Therefore, it is unwise of authors, not to react to suggestions for improvement and positive criticism contained in the reviews. On one hand, as most of us will admit, a person not directly involved in the study that is presented in a ms is much more likely to spot mistakes, to point 
out inconsistencies and to miss a lack of clarity than the authors themselves. On the other hand, it is likely that the journal chosen for the second try will appoint the same expert as the previous one. Finding one's suggestions ignored will not change the view of a reviewer to the better. In our opinion, this matter should be handled in a case by case manner. Requiring authors to state whether the ms has been rejected by a journalincluding a statement on the reasons of the rejection and the changes that have been made in reaction to the comments - could be required by the journal editors, but should remain with them and not be passed on to reviewers in order not to prejudice their decision. Only in case a reviewer states, that she/he has reviewed the ms before, these facts should be revealed. Publishing a 'black list' of rejected mss is a cruel measure which will discourage especially young people to submit their first papers to top journals fearing that their reputation will be damaged when they hardly have gained one. The persons that should be discouraged - namely those established scientists who tend to become more negligent with time-have a much tougher hide and usually resort to declaring negative reviewers incompetent. We will not suggest such a procedure to the publisher of PSZN: Marine Ecology. Lastly, as Nando Boero in his contribution rightly states, mss that have been rejected by several major journals may still become classics when finally published.

Ferdinando Boero (Member or past member of the editorial board of: Cahiers de Biologie, Marine Ecology Letters, Italian Journal of Zoology, Journal of Evolutionary Biology, Marine Ecology Progress Series). I concur with those who think that resubmission of rejected mss is not a big problem for editors, besides the overload of work. A bad ms is supposed not to pass through the meshes of the net; if it does, then the net is not so good. I think that asking to report own failure is against the right of privacy, and it poses the potential contributor in a bad light, since resubmission means that s/he considered the journal as a 2 nd, or $3 r d$, or 4 th... choice.

There is a much more pressing problem that affects not the work of the reviewers but the content of the journals. All journals ask the authors to state that the article has not been submitted for publication in another journal. It happened to me, however, that referees wrote that they already reviewed for another journal a very similar paper by the same authors. And that it had been accepted. The title was slightly different, but there was a substantial overlap in ideas and data. I think that this is a much greater problem. A successful paper can be sold several times. One thing is to have an idea and push for its acceptance by proposing it from several tribunes (like it happened for supply- side ecology), another thing is to squeeze as much juice as possible from the same set of data. It is common to see that the same authors publish a series of papers on different aspects of the same topic that might well be a single, comprehensive paper. The Canadian Journal of Zoology sent me 2 of these papers and I suggested merging them. In each paper, the sister article was not even cited!

I proposed in a former contribution to this forum to publish the titles of all the mss that a journal receives for publication. It has been called a 'black list', recalling McCarthyism to me. Of course authors should be aware that this is the game they play, and the problem we are discussing now stems from attitudes that are to be discouraged. Asking them to state explicitly the black career of their article, though, is even worse. It is like asking a person who is looking for a job to state how many times s/he applied and was turned down. I am proud to say that one article I sent to the American Naturalist has been rejected because it contained too much natural history! But I do not know if I will be happy to tell to the next journal that I chose the American Naturalist first.

Josep-Maria Gili (Editor, Scientia Marina). Let me begin by thanking the editor of this TS for again soliciting my opinion concerning the peer review system. After 7 years of work for re-launching Scientia Marina as a journal, I am looking at the problem more from the vantage point of an author than an editor. My purpose is to try to put my experience as a contributor to a series of journals to good use, and my feeling is that there is no easy fix for the issues involved. Like other respondents to the present query, in spite of everything I still think that the peer-review system is the best we can have at the present time. It seems to me that perhaps what is called for is a critical look at underlying attitudes that address the underpinnings of the scientific publishing system rather than to address certain specific attitudes like authors who resubmit their mss to other journals without taking into account the reviewers' comments and suggestions. I view this behaviour as exceptionally unscrupulous and heinous, and it seems to me that the proposals made by the various contributors will be extremely helpful in putting a stop to this type of unprofessional conduct on the part of the authors who engage in it.

In any event, we should not lose sight of the fact that as scientists we are all under pressure from the 'publish or perish' system. This system is a source of serious difficulty for science in general and for scientific publishing in particular. The people who came up with the peer review system are the same ones who have invented the journal and author ranking systems as well. I admit that ways of assessing scientific activity are needed and that publications are our best call- 
ing card. Yet at the same time, with the system we have in place today research careers are often judged more by the journals in which papers have been published than by the contribution represented by the work itself. Can it be that journals are no guarantee of research quality? I truly believe this to be the case, though only in part of course. Journals compete among themselves for the best papers and place too much stock in it. If we are truthful, we will have to concede that many papers are designed from the very outset more with a view to the journal we want to publish them in than to their actual content and relevance. We should also admit, though doing so comes hard, that as referees we review papers according to the journal to which a paper has been submitted for publication. This competition among journals, reviewers, publishers, and so forth gives rise to quite a complicated and sometimes embroiled situation that only makes our work harder, since to a large extent our work depends on access to good sources of information. We no longer think about a journal's scope but rather about its index rating.

The use of concepts like 'descriptive', 'experimental', 'broad interest', etc. when evaluating a paper is another important aspect. To gain publication many authors often submit their work to journals located outside their geographic area and even outside their subject matter, which of course complicates assessment still further. Papers dealing with a wide variety of topics can be found in journals that publish very little on the subjects in question, and they are quite often of questionable value. As authors we should acknowledge that not everything is publishable. In addition, in many cases we split up the information so as to be able to derive a larger number of publications by publishing the minimum quanta of information content, another attitude that can only be regarded as deplorable. As editors we need to recognize that high-quality work that is well done will transcend geographical and conceptual boundaries. My impression is that we have fallen into a vicious cycle and that it is by no means going to be easy to extricate ourselves from it.

Let me apologize for the broadly general nature of my take on this question, but I am deeply concerned about the system in which we are entangled and its implications. Scientific publishing is a big business that has been erected on our biggest failing, our pride. I am as much a part of the system as anyone, since I participate as a reviewer and at the same time I make submissions as an author. But we contribute to the system free of charge with our work as authors and as reviewers, whereas we have to pay for all the information services that we use. Though it may well hurt to admit it, this situation is completely opposite from the situation that exists in other areas of publish- ing (novels, newspapers, etc.). This thought causes me to be quite stringent in respect of our attitudes as authors and to endeavour to submit to journals that are the most appropriate ones for our work in terms of geographical scope and content, to lower the likelihood of having to resubmit it elsewhere. It thus behooves me to realize that not all my results will necessarily deserve to be published and to meticulously review my work in light of the referees' comments. There is certainly scope for error on all sides. As a referee, it behooves me to apply the same review criteria to all mss, irrespective of the journal to which they have been submitted. As an editor, it behooves me to design a journal that is both open and objective in its scope and to be fair to both authors and reviewers. It is my conviction that we still have a very long way to go to make the peer review system into what we all think it should be, and to do this first and foremost we all have to start out by taking a more critical stance as authors and a less subjective stance as reviewers and editors. Be that as it may, I believe that we are not going to get very far unless we are at the same time able to improve the operation and objectivity of the system of scientific publishing as a whole.

Katja Philippart (Editor-in-Chief, Journal of Sea Research). As an editor and an author, I am always delighted to find that so many colleagues are willing to put so much time and effort in scrutinizing a ms with the best interest of the authors, the paper and, in particular, good science at heart. In order to restrict the workload for everyone involved, I welcome the initiative to discuss how to make the reviewing process as time-effective as possible. Of course, we do resent it when authors submit an unchanged ms to our journal that turns out to have been rejected by other journals for all the right reasons (bad science). But on the other hand, we do have to be very careful not to do injustice and lose valuable scientific information when trying to prevent this malpractice.

At our editorial office, we appreciate the honesty of authors who state that their ms was rejected by another journal, and enclose the reviews and an accompanying letter explaining why they think the publication of their (revised) ms should be considered. It is up to the editors to decide if such a ms is directly rejected by our journal as well, or will be sent out for refereeing. For our journal, we do not advocate to introduce countermeasures (such as compiling lists of rejected mss), because it is unfair to authors whose mss were rejected for the wrong reasons (e.g. out of scope, biased referees) and is bound to fail (e.g. simply switching the author's names or a change of the title will prevent it popping up more than once on the lists). In addition, doing this properly will probably take far more time than it will save. 
Matthias Seaman (Assistant Editor, Marine Ecology Progress Series). Many scientists regard the review process primarily as a means of helping editors decide whether or not to accept a ms. Two other functions are often underrated: (1) peer review is an essential element of scientists' life-long learning; (2) reviews serve to improve the quality of a ms. A case in point is a recent ms which the authors innocently submitted simultaneously to a MEPS Contributing Editor (CE) and to our offices; it was reviewed by 8 referees (the $\mathrm{CE}$ and 3 of his reviewers, plus 4 other reviewers selected by our office), and the final outcome was an excellent paper. The authors are primarily responsible for their ms and hence must always have the last word, but those who disregard reviewers' suggestions are foregoing an important opportunity, in addition to wasting the reviewers' and editor's time.

I am somewhat surprised at the suggestion that an editor might be offended to find out that a ms was originally submitted elsewhere (making her/his own journal the second choice). What counts is the science. MEPS occasionally receives a ms rejected elsewhere. We will not accept it without additional review, but if we conclude that the author(s) are justified in protesting against the previous editor's rejection, we will employ an abbreviated review procedure, e.g. with 2 instead of the usual 4 reviewers; these referees will receive all previous reviews and they will be asked to confirm that the ms submitted to MEPS has been appropriately revised. If that is the case, final judgment of the ms can be made much faster than if the authors had failed to mention the rejection. We believe that our procedure works to the authors' advantage, and it avoids duplication of effort.

\section{SUMMARY}

Academic advancement, research funding, and institutional reputations increasingly depend on peer reviewed publications: an acknowledged measure of quality. The 'publish or perish' atmosphere tends to overtax the quality control system. And peer review is sometimes perceived as an obstacle rather than an opportunity to obtain advice and assistance from colleagues.

Some authors abuse the reviewers' services by submitting rejected mss to another journal without taking the previous criticism sufficiently into consideration and without revealing that their ms has been reviewed and rejected. They should disarm criticism in a revised version of their ms before re-submitting it elsewhere.

To emphasize the importance of such a policy, Marine Ecology Progress Series (MEPS) has modified the guidelines for authors: if a ms has previously been submitted to another journal 'the former reviews and author's replies should be enclosed.' Some contributors disagree with this policy; e.g. for Limnology and Oceanography (L\&O) resubmission is not an important issue, and L\&O will not follow the lead of MEPS.

The Journal of Experimental Marine Biology and Ecology (JEMBE) also asks authors to notify the editors if submitted mss have already been considered by other journals, and to forward the referees' comments and information on how they addressed these. The editors of JEMBE frequently have mss returned from referees saying that they had recommended rejection before, and that the revision was inadequate.

Nevertheless, most contributors to this TS do not support the view that authors resubmitting mss rejected from other journals should have to state this and give details about the ms' history. Asking to report their failure may place the authors in a bad light, since resubmission means that the journal was not their first choice.

While most contributors know of authors who resubmitted mss to other journals without considering the criticism of former reviewers, several believe that this is actually a minor problem. Most reviewers return mss they have seen before. How severe is the problem and is it a real burden for referees and editors? For some journals (e.g. Acta Zoologica, Aquaculture Nutrition, Aquaculture, Sarsia, Estuarine Coastal and Shelf Science, Marine Biology, PSZN Marine Ecology) this is not a serious problem and they are not likely to adopt a new policy.

Mss are rejected for different reasons. Often the ms is considered not suitable for the journal or of insufficient quality. Different journals have different standards. It is therefore fair to give authors a chance for a second opinion on their mss. Submitting a ms that has been rejected by one journal to another one is a legitimate practice, because reviewing is done by peers (not superiors) with whom an author may disagree. Mss rejected by major journals may even become classics when finally published.

Authors should be appreciative of the time reviewers donate on their behalf and, even if they disagree, should address the reviewer's concerns before resubmission. Editors do not expect authors to bow to every reviewer's criticism, but they usually require a detailed list of changes made (or not) in response to each criticism or comment offered by the reviewers.

Authors should be grateful for constructive criticism that improves their mss, and should view peer-review as a gift from their colleagues. They should also consider that their published work is a permanent record and a lasting reflection of their reputation. Authors that resubmit their mss to other journals without taking into account the reviewers' suggestions are scorned by all 
contributors to this TS, especially when the mss have been rejected because of poor science.

Publishing a 'black list' of rejected mss might discourage especially young colleagues to submit their first ms to a top journal fearing that their reputation will be damaged when they hardly have gained one. Most journals, like the Journal of Sea Research, do not advocate introducing countermeasures because it is considered unfair to authors whose mss were rejected for the wrong reasons (e.g. out of scope, biased referees). Editors must be careful not to suppress valuable scientific information.

In general, editors choose their reviewers among the most experienced and respected scientists in their field; but editors could reduce the load of well-known specialists by including one or 2 'juniors' along with a 'senior'. Editors should acknowledge the receipt of a review report and inform the reviewers of the fate of a ms.

More statistics are needed and co-operation among journals. Cross-checking could throw more light on how effective the peer-review system is and to what extent misuse is a problem.

Editorial responsibility: Hans Ulrik Riisgård, Kerteminde, Denmark
Acknowledgements. I highly appreciate the willingness of all invited editors and reviewers to contribute to this exchange of opinions. Thanks are due to Otto Kinne and Matthias Seaman who helped to polish this TS.

\section{LITERATURE CITED}

Anonymous (2003) Editorial. Aquac Nutr 9:65

Burnham JC (1990) The evolution of editorial peer review. $\mathrm{J}$ Am Med Assoc 263:1323-1329

Fee E (1998) A message from the editor: reviewing for L\&O. ASLO Bulletin 7(3):5

Kinne O (1988) The scientific process - its links, functions and problems. Naturwissenschaften 75:275-279

Kinne O (1999) Electronic publishing in science: changes and risks. Mar Ecol Prog Ser 180:1-5

Kinne O (2003) The scientific process: new forces attempt to enter the scene. Mar Ecol Prog Ser 254:1

Kronick DA (1990) Peer review in 18th-century scientific journalism. JAMA 263:1321-1329

Rennie D, Flanagin A, Smith R, Smith J (2003) Fifth international congress on peer review and biomedical publication. Call for research. JAMA 289:1438

Riisgård HU (2000) The peer-review system: time for reassessment? Mar Ecol Prog Ser 192:305-313

Sweitzer BJ, Cullen DJ (1994) How well does a journal's peer review process function? JAMA 272:152-153

Final version accepted: August 18, 2003

Proofs received from author(s): August 19, 2003

The text of this and a previous Theme Section (TS) dealing with the peer-review system is available at the Inter-Research (IR) web site (www.int-res.com/journals/meps/themeSections.html). The debate will continue on IR's Forum on the 'Peer-Review System' (www.int-res.com/forum/peer_review.html). Readers are invited to express their opinions. Please send your text (brief and concise) to the Forum Editor, Hans Ulrik Riisgård, email: hur@biology.sdu.dk 